\title{
sciendo
}

\section{On the issue of the use of bacteriological weapons, IT technologies, and security.}

\author{
Ludovico De Serio \\ Regional State University of Aqtobe "K. Zubanov", Kazakbstan \\ email: ludovico.deserio@gmail.com \\ Vadim Sarsenbayev \\ North Kazakhstan State University "M. Kozybaev", Kazakbstan \\ email:vadimcool314@gmail.com \\ Vladislav Semenyuk \\ North Kazakhstan State University "M. Koaybaev", Kazakhstan \\ email: karina2011_12@mail.ru
}

\section{DOI: $10.2478 /$ gssfj-2020-0014}

\begin{abstract}
This article describes modern technologies that affect the statehood and politics of countries in general. The article deals with the main issues of security in the field of medicine and IT technologies. The study examines the impact of the pandemic and cybersecurity on the lives of citizens in general. An analysis of the technologies that are used in countries in cases of a pandemic is carried out and the issues of the influence of the Internet space on the consciousness of people are considered.
\end{abstract}

Key words: technologies, cybersecurity, COVID-19, medicine, Internet space.

The state of protection of the vital interests of the individual, society from internal and external threats is an important task of any state. To date, COVID-19 has shown how diseases can spread quickly, and what types of damaging factors they carry. An important role in the spread of these diseases is played by the Internet space, where, as a result of the dissemination of inaccurate or false information, people who acquire them can face major consequences for themselves or their loved ones. The Internet space can also be used by any ill-wishers, with the purpose of disseminating certain types of information and infecting people.

\section{Bacteriological weapons, or man-made epidemics}

With its violent outbreak, Covid-19 made all the world aware of the fact that worse scenarios could actually take place if a more severe disease should spread, or "biological weapons" were to be used. From the definition of "Biological weapons" - these are pathogenic microorganisms or their spores, viruses, and bacterial toxins that infect people and animals, intended for mass destruction of the enemy's manpower and population, farm animals, crops, contamination of food and water 
sources, as well as damage some types of military equipment and military materials. Biological weapons also include delivery vehicles for pathogenic microorganisms and animal vectors. The damaging effect of biological weapons is based primarily on the use of the pathogenic properties of lethal microorganisms and toxic products of their vital activity. As it is now known, biological weapons or diseases can be spread in various ways, including through "terrorist carriers of the virus": these sabotaging strategies can be used in crowded city centers, making use of human or mechanic carriers, or simply by contaminating water or food. The use of IT technologies, including the use of the Internet space, as well as the spraying of viruses using UAVs, can make the situation even more critical. In a hypothetical scenario concerning the use of UAV for spreading a pathogen (Figure 1), it will be highly difficult to identify the flying objects as means of dispersion due to its discretion in terms of dimensions and generated noise, especially if the scenario were to be taking place in a crowded public space.

Moreover, packages, bags, boxes, containers dropped from airplanes or left by people can all carry a potential threat; in fact, while upon first detection a finding in the form of an "infected object" may not even raise suspicion since diseases and biological weapons often have an incubation period, during which the disease does not manifest itself, and the affected person would not be noticing any visible symptoms. During this period (that often lasts from 2 to 12 days) there will then be a high chance that a high number of people would get in contact with the person who first encountered the "infected carrier". Some diseases (plague, cholera, anthrax) can be transmitted from a sick person to a healthy one and, quickly spreading, generate an epidemic outbreak. It is rather difficult to establish the use of bacterial agents and to determine the type of pathogen, since both microbes and toxins are colorless, smell-less, and tasteless, and their effects can become manifest after a long period of time.

The detection of bacteria and viruses is possible only through specific laboratory tests, which usually take a long time, making it difficult to carry out measures in time to prevent a potential epidemic.

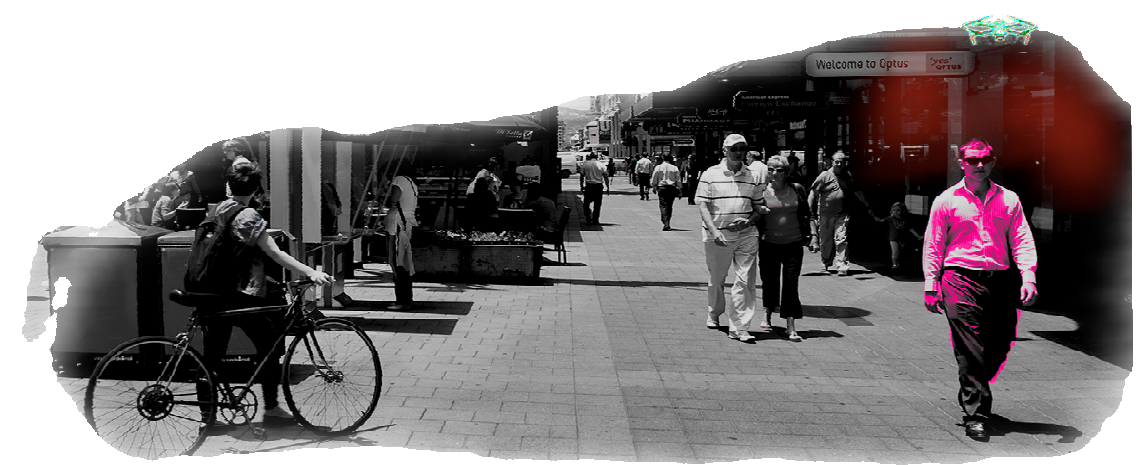

Figure 1 - A possible scenario of an epidemiological attack carried out through UAV

Currently, biological weapons are outlawed worldwide: several conventions have been adopted prohibiting their development, storage, and use. However, despite all international agreements, the press regularly reports on new developments of these prohibited weapons. Many experts believe that bacteriological weapons are in some 
ways even more dangerous than nuclear ones: their properties and features are such that they may well lead to the destruction of the human race on the planet. Biological weapons have many features, the main one of which is the ability to cause mass diseases in humans (epidemics), animals (epizootics), and plants (epiphytotic). A small number of microbes is sufficient for a major infection. Once in the body, microbes multiply rapidly, cause the disease, and then, due to contact of people with each other, through the excreta of patients, air, water, food, as well as through various vectors, usually insects, the disease can become very widespread.

In this case can be used microbes (viruses, bacteria, fungi) - pathogens of brucellosis, tularemia, anthrax, plague, cholera, glanders, diphtheria, typhoid fever, fever, encephalitis, smallpox, influenza, and many other diseases. The damaging effect of biological weapons does not appear immediately, but after a certain time, depending on both the type and number of pathogenic microbes or their toxins that have entered the body and on the physical state of the body. Some of the diseases resulting from infection, called contagious (plague, smallpox, etc.), can then be transmitted from the affected to the surrounding healthy people through the air, bites of bloodsucking insects, and in other ways. Diseases called non-contagious (anthrax, tularemia, etc.) are practically not transmitted from sick people to healthy people. The classification of typologies of diseases is described in Fig. 3.

\section{Diseases}

$\begin{array}{ll}\begin{array}{l}\text { Contagious } \\ \text { (Plague, smallpox, }\end{array} & \begin{array}{l}\text { Non-contagious } \\ \text { (Anthrax, }\end{array} \\ \text { cholera, flu) } & \text { brucellosis) }\end{array}$

Figure 2 - Classification of diseases 


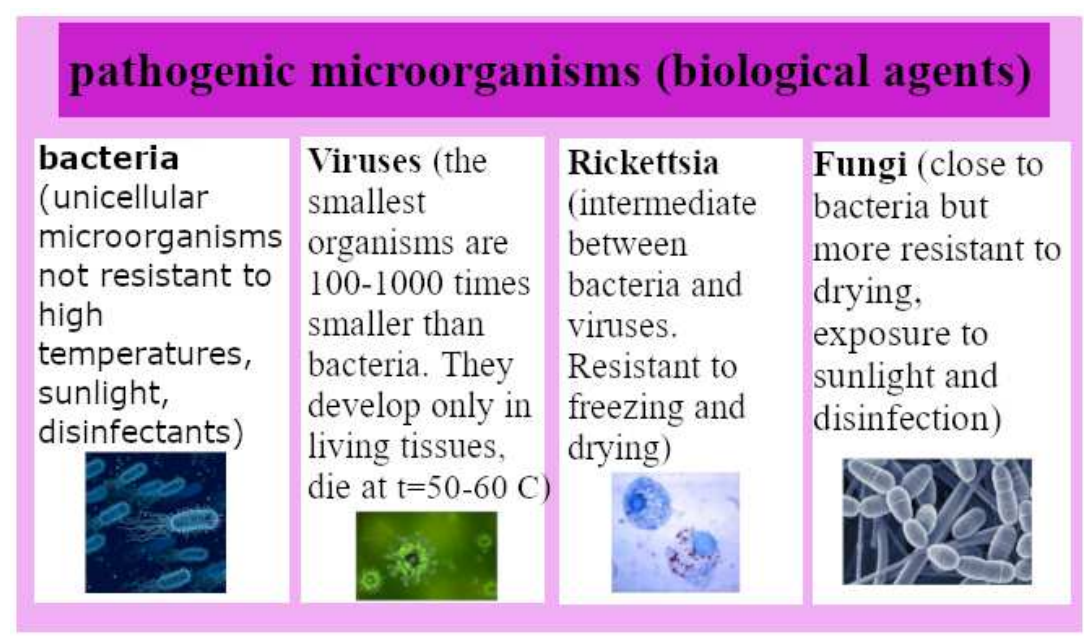

Figure 3 - Classification of biological agents

\section{The case of Coronavirus}

World health organization works closely with international experts, governments, and partners to rapidly generate scientific evidence about the diffusion of new viruses, track their spread and assess virulence, and advise countries and populations on how to protect health and prevent the spread of the outbreak. Considering the current epidemic, the spread of the SARS-CoV-2 virus seems to have originated from the Chinese city of Wuhan, leading to a rapid and massive outbreak of the disease. According to the latest data, about 34 million cases of coronavirus infection have been identified in the world today. 2019-nCoV coronavirus infection is a potentially severe acute respiratory infection, caused by the SARS-CoV-2 coronavirus (2019$\mathrm{nCoV})$. It is a dangerous disease that can occur both in the form of an acute respiratory viral infection of a mild course and in a severe form. The most common complication of the disease is viral pneumonia, which can lead to acute respiratory distress syndrome and subsequent acute respiratory failure, in which oxygen therapy and respiratory support are most often required. The most common symptoms of the disease are fever, fatigue, and dry cough. In rare cases, the virus infection in children and adolescents, presumably, can lead to the development of an inflammatory syndrome. The virus spreads by airborne droplets through the inhalation of droplets with the virus sprayed in the air when coughing, sneezing, or talking, as well as through the ingress of the virus on a surface with subsequent entry into the eyes, nose, or mouth. Effective preventive measures include frequent handwashing and good respiratory hygiene. The disease is caused by a new virus against which people initially did not have a previously acquired immunity; people of all ages are therefore susceptible to infection. 


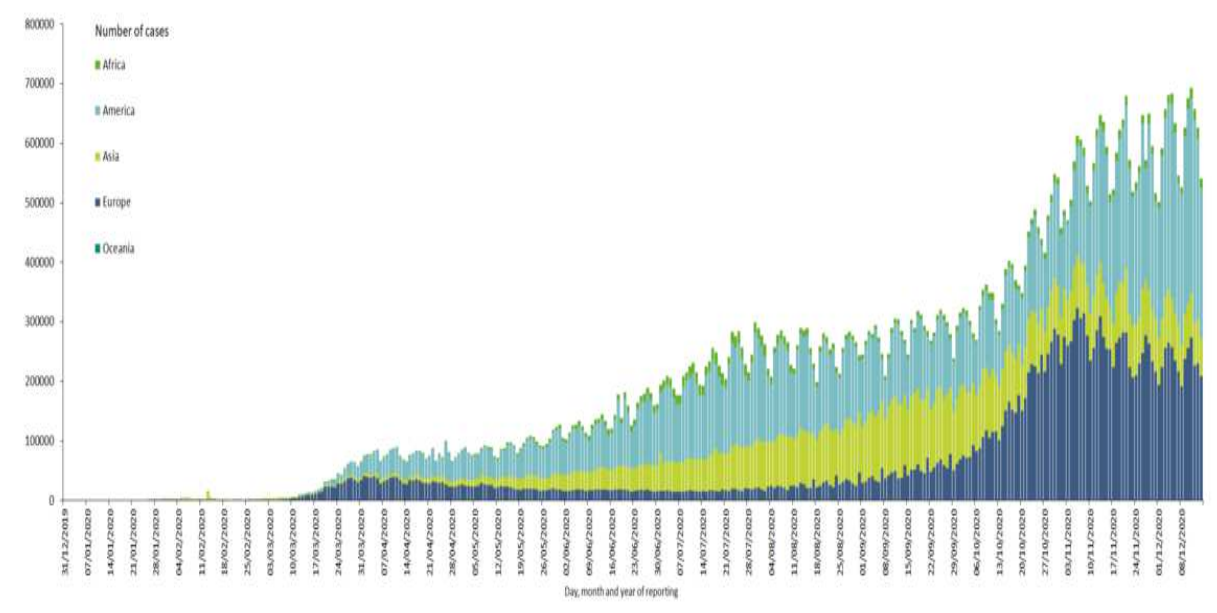

Figure 4 - The number of infected people worldwide. Source: ECDC

It should be noted that high morbidity and mortality rates were very common in people of the past. Huge crowds of people, vague ideas about sanitation and hygiene, poor nutrition - all these factors contributed to creating excellent conditions for the development of infectious diseases in society. Therefore, the first attempts to use infections to defeat enemy troops were made several thousand years ago. The Hittites, for example, simply sent people sick with tularemia into the enemy camp. Moreover, in the Middle Ages, new methods of delivering biological weapons were invented: the corpses of people and animals who died from some fatal ailment were thrown into besieged cities with the help of catapults.

At the same time, nowadays, on platforms where there can be a large number of people such as social media, false information can be spread very effectively, aggravating the situation of infection.

\section{Online dangers in a pandemic scenario}

Over the long weeks of quarantine, it was immediately apparent that once we were forced to freeze our bodies in individual homes to prevent their mutual contagion, we immediately relied on our digital identities - especially, within social networks - to continue to carry out the life abruptly interrupted by the pandemic.

According to estimates by the consulting firm Boston Consulting Group (Coden, Close, Bohmayr, 2020) hundreds of millions of people globally are now at home engaged in smart working, taking school classes online, shopping using e-commerce platforms, or having long conversations via video conferencing programs. However, if on the one hand, the internet is proving to be an indispensable tool in this situation, the other side of the medal shows a huge increase in cyber risks to which a user potentially comes into contact.

According to Bitdefender, a leading global cybersecurity company, in March alone malware reports related to the coronavirus emergency increased by over $475 \%$ as cybercriminals act opportunistically and unethically taking advantage of this period 
of uncertainty to spread malware, launch phishing campaigns and operate online fraud attempts against healthcare facilities already hard hit by the situation.

As the number of users connected to the network increases, so does the risk of scams, data theft, blackmail, and other cybercrimes.

Ensuring state security - a complex of political, economic, social, military, and legal measures to protect the interests of citizens should include methods for monitoring and researching the Internet space - becomes, therefore, the priority for any government worldwide. Digital security has defined a set of measures aimed at protecting the confidentiality, integrity, and availability of information from virus attacks and unauthorized interference. Information technology is becoming an integral part of the hospitality industry. It is difficult to imagine a modern hotel without payment systems, without online booking, "smart technology" and other things we are used to. Currently, one of the most important issues is the issue of information security. Consider the scenario of spreading disinformation on the Internet

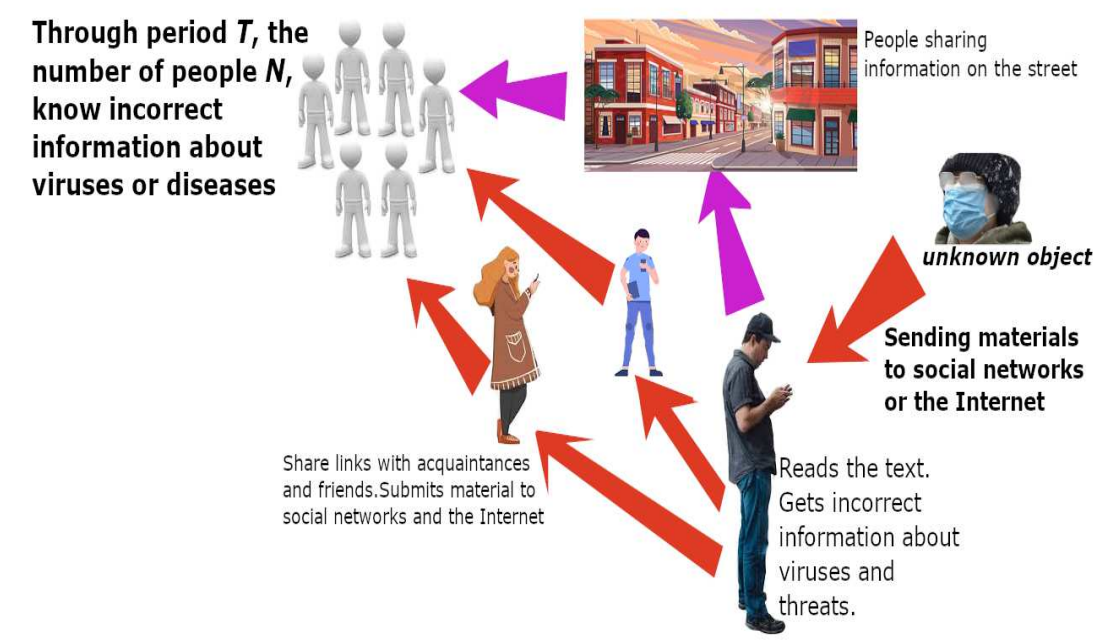

Figure 5 - Scheme of "word of mouth" operation on the Internet

Another of the most common risks is that of information theft, which occurs when a criminal hacker gets hold of someone's personal data and then resells it on the Dark Web, perpetrating scams of all kinds and stealing more than just money. Whether it's private information, credit card details, home banking access codes or confidential work information, it's all sensitive and vital information, the theft of which makes people extremely vulnerable.

If we consider the scenario when information about a person is used to infect him with a virus or spread misinformation. Information about a person can be what types of medicines he or she uses, which social groups he is in, his political and personal views and so on. Therefore, having taken possession of such personal information as these personal data about his/her drug uses, he/she could be infected with the use of altered drugs. In such a scenario, it is important that a person will not doubt the contaminated medicine if the criminals use the packaging of the medicine he often uses. The data can also be used to create letters from doctors about the 
recommendation of a poisoned medicine, or deception with insurance policies. It is important here raise awareness on not providing personal info online and make use of specific software to protect one's personal computer. In modern times of cybersecurity, humans are still the most vulnerable element. Therefore, if we consider scenarios of mass infection of people or theft of large amounts of user data, criminals will also use social engineering methods. Social engineering is used to ferret out as much data as possible about the people who are the target of criminals.

In another possible scenario of infection of the population, one can consider the possibility of infections spread by criminals on the Internet, a phenomenon that is to be considered in those practices defined as "bio-terrorism" (figure 6).

Let's consider how online shopping is very common in modern times. Pop-up ads are often found on almost all popular websites, as well as applications on mobile devices, often the elderly or children may be influenced by ads on certain products (for example drugs or medicine), where they cannot check the safety of drugs and information about the manufacturer. This opportunity can be used by criminals or terrorists to distribute contaminated drugs. To do this, criminals can use links to social networks or resources on the Internet. Viruses or bacteria can be placed in ointments or sprays, after which, after a certain period, the infection will occur. Over time, people around them can also become infected. The most difficult thing in treatment would be to find out the cause of the infection since the majority of people will not think that they have contracted the infection through the use of a spray or ointment. After a certain period, large areas could then become infected, and since the infected product is sold online, the possibility of reaching any part of the globe would be very much realistic.

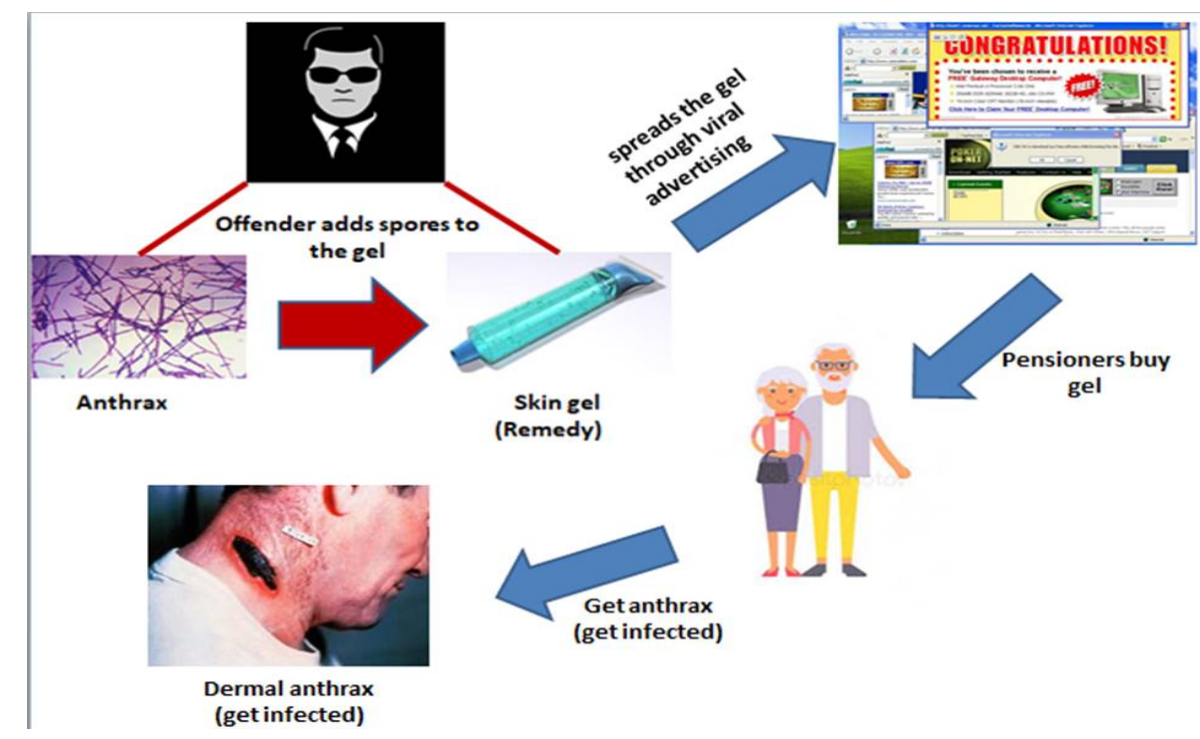

Figure 6 "Scenario of distribution of contaminated drugs on the Internet" 


\section{Artificial intelligence and epidemics}

Today artificial intelligence includes software with a set of algorithms and methods that can solve intellectual problems in the same way as a human would do. For example, artificial intelligence can: predict various situations; evaluate information, and formulate a final assessment; analyze data, and look for hidden patterns. That is, artificial intelligence and modeling systems can be used to create more complex and more terrible bacteriological weapons because using IT technologies it is possible to solve not only the tasks of improving weapons but also to predict the growth of epidemics and measures that the state will take to combat the virus. That is, artificial intelligence and modeling systems, in the future, will be able to serve in order to harm countries and their populations.

To date, the development of bacteriological and other weapons has advanced significantly. Since in modern weapons production, computer technologies and mathematical modeling are actively used. Modern mathematical and computer models make it possible to predict the behavior of bacteriological weapons or the course of infection in a certain area, taking into account weather conditions. When designing modern bacteriological weapons, it is also possible to take into account the use of drugs by the population, that is, to predict how a virus or bacteria will behave when interacting with drugs. To conduct research on the effect of bacteriological weapons, computer models created using programming languages can be used, which makes it possible to simulate a huge number of options by changing a certain parameter in the model.

\section{Conclusion.}

The most important aspect of state security in the modern world, where there are opportunities for the emergence of mass diseases of people, is the government's quick response to the threat on different levels. At the same time, it should be noted that an important security factor is the supervision of the Internet space, where incorrect information can be spread, potentially aggravating the situation in the event of a mass illness of people. Through the Internet resources, information can be sent to every home, to every person exerting an influence on him or her, after which he/she can act not as he should. That is, together with the control of the borders and perimeters of the state from the spread of epidemics, it is worth controlling the Internet from incorrect information.

\section{References}

Supotnitsky M.V. (2013). Biological warfare. Introduction to the epidemiology of artificial epidemic processes and biological lesions: monograph. - M "Department", "Russian panorama".

G. Pocheptsov (2019). Disinformation, Kiev.

\section{Web references}

https://www.who.int - «Questions and answers on COVID-19»

https://www.bcg.com/publications/2020/covid-remote-work-cyber-security "Managing the Cyber Risks of Remote Work", Boston Consulting Group, 20/03/2020 